\title{
Anthology of Russian Oral Epics
}

James Bailey

Sometime in the spring of 1998 the Anthology of Russian Oral Epics translated by James Bailey and Tatyana Ivanova will be published by M. E. Sharpe as part of the series "Folklores and Folk Cultures of Eastern Europe." The anthology consists of a general introduction to the Russian epic, translations of thirty songs, a glossary, and a bibliography of selected studies in English and Russian. An introduction to each song surveys interpretations, summarizes the details of the plot as it appears in different variants, and explains references and allusions. For the most part songs not translated previously have been included so as to add to the variants available to an English reader. Examples of all subgenres of Russian epics have been selected: heroic epics, bylina, novella, dukhovnye stikhi, fabliaux, and skomoroshina or satirical songs such as the nebylitsa. Two historical songs and one ballad have also been translated so as to contrast these genres with the epics and also to show the breadth of the singers' repertory. The texts have been taken from most major collections and chronologically cover the recording of Russian epics from the middle of the eighteenth century (Kirsha Danilov) to the 1950s and 1960s when the tradition was dying out. What V. M. Gatsak calls a "folklorizing translation" has been provided, that is, an effort has been made to maintain the repetitions so characteristic of oral poetry as far as possible in English. The identity of the lines has also been preserved so as to convey a sense of poetry and of parallelism. No attempt has been made to duplicate the rhythm of the original but the translations have 
been made rhythmical in English without any metrical regularity.

The anthology is intended for courses on Russian folklore, for folklore courses on epics, and as an introduction to the Russian epic for folklorists in other traditions. 